\title{
Complex energy networks: energy-ecological efficiency based evaluations towards the sustainability in energy sector
}

\author{
Maria Alessandra Ancona ${ }^{1 *}$, Michele Bianchi ${ }^{1}$, Lisa Branchini ${ }^{1}$, Andrea De Pascale ${ }^{1}$, Francesco Melino ${ }^{1}$, and Antonio \\ Peretto $^{1}$ \\ ${ }^{1}$ Alma Mater Studiorum Università di Bologna, Department of Industrial Engineering (DIN), Viale del Risorgimento 2, 40136 \\ Bologna, Italy
}

\begin{abstract}
In the last years, international programs in diverse sectors and national frameworks have been driven by the need of a sustainable growth, in a green economy perspective. In order to reduce the energy losses/dissipations, as well as the fossil fuels employment and related pollutant emissions, indeed, the spread of combined heat and power units and/or renewable sources generators is promoted into both the electrical grids and the thermal networks but are often in conflict with the economic aspects. In this context, the optimal management of complex energy networks - including, in particular, smart district heating - may lead to the achievement of important goals from the environmental and sustainability viewpoints. The aim of this paper is to develop a preliminary methodology for the complete evaluation of complex energy networks, considering energy, economic and environmental aspects. With this purpose, a case study consisting in a network for the fulfillment of electrical and thermal needs of the connected users will be analyzed, considering different scenarios in terms of energy generation mix and operation and applying different optimization software. In addition, the carried out evaluations will allow to set the basis for the discussion about the future of energy policies and possible incentives towards the sustainable development of the energy sector.
\end{abstract}

\section{Introduction}

The last years have been characterized by a growing attention to the sustainability in the energy sector, which involves the need to increase both the penetration of renewable sources and the energy conversion efficiency towards the reduction of the fossil fuel consumption and, thus, of the greenhouse gas emissions [1]. To this respect, both international and national legislations promote the spread of distributed generators, as well as the district heating networks for the thermal needs fulfillment [2]. Indeed, the European Union has set the target to make Europe a climate-neutral continent by 2050 , requiring a modification in the greenhouse gas emission reduction goals for 2030 , which need to be increased from $40 \%$ to either $50 \%$ or $55 \%$ [3]. To achieve this goal, public and private investments in energy efficiency, renewable energy, new low carbon technologies and grid infrastructure are planned.

In addition, in order to allow a further increase in the energy production and distribution efficiency, the socalled complex energy networks (i.e. electrical, thermal and cooling distribution networks) represents a key point [4]. To this respect, it is fundamental to optimize the production mix and the operation of each system, in order to maximize the renewable energies exploitation and minimize both the economic and the environmental impacts. In particular, the actions towards the economic and the environmental goals are often conflicting, requiring high investments for the energy systems which maximize the environmental sustainability.

In this context, the aim of the paper stands in the development of an energy-environmental methodology for the evaluation of complex energy networks. In detail, in order to evaluate the environmental aspects related to the energy production and distribution, in this study the definition of an energy-ecological efficiency from literature has been extended for the first time to the complex energy networks, including comparative considerations about several energy systems for electrical, thermal and cooling production. Furthermore, the new developed parameter has been applied to a case study represented by a middle size network for the complete fulfillment of the connected users' energy needs, allowing to demonstrate the need of supporting actions (e.g. incentive policies) from the lawmaking bodies.

\footnotetext{
*Corresponding author: maria.ancona2@unibo.it
} 


\section{Energy-environmental efficiency for complex energy networks}

The energy-ecological efficiency has been firstly developed by Cardu and Baica in [5] as an indicator of the environmental performance of energy systems, based on the atmospheric emissions of the main air pollutants. A variant to the first expression of this parameter has been then presented by the same Authors in [6], leading to the achievement of the current definition. In addition, further studies apply the energyenvironmental efficiency to thermoelectric power plants [7] and to hybrid energy systems [8], demonstrating the viability of this approach for the evaluation of the environmental impact in the energy generation field. In this context, the goal of this study is to apply the energyenvironmental efficiency for the first time to the complex energy networks, in order to give a methodology for the networks design and operation optimization including both economics and sustainability aspects.

In detail, for each energy system, the ecological efficiency $\left(\eta_{\text {eco }}[-]\right)$ is defined as [6]:

$\eta_{\text {eco }}=\left[\frac{0.204 \cdot \eta_{I}}{\eta_{I}+I P} \cdot \ln (135-I P)\right]^{0.5}$

being $\eta_{I}[-]$ the first law efficiency and $I P[\mathrm{~kg} / \mathrm{MJ}]$ the pollution indicator.

A value of $\eta_{\text {eco }}$ equal to 0 means a maximum environmental impact, while a value of $\eta_{\text {eco }}$ equal to $100 \%$ is obtained when no pollutant emissions are ascribable to the analyzed energy system. These extreme conditions are attributed respectively to sulfur and hydrogen [6].

In addition, the pollution indicator is calculated by means of the following expression:

$I P=f_{\mathrm{CO}_{2}, e q} / L H V$

where $f_{\mathrm{CO}_{2} \text {,eq }}\left[\mathrm{kg}_{\mathrm{CO} 2} / \mathrm{kg}_{\text {fuel }}\right]$ is the $\mathrm{CO}_{2}$ equivalent emission factor and $L H V[\mathrm{MJ} / \mathrm{kg}]$ is the lower heating value of the fuel. These parameters can be easily calculated once known the fuel in input to the analyzed energy system.

The idea at the basis of this study is to extend this approach to the complex energy networks (i.e. the electrical, thermal and cooling energy distribution networks), by considering the contribution of each connected energy system to the fulfillment of the network's needs. As a consequence, for a complex energy network, it can be written:

$\eta_{\text {eco,network }}=\sum_{i=1}^{N e s} \eta_{e c o, i} \cdot x_{i}$

being Nes the number of energy systems within the considered network, $\eta_{e c o, i}[-]$ the ecological efficiency of the system $i$ and $x_{i}[-]$ the weights, represented by the contribution of each energy system to the production of the energy totally required by the network $\left(E_{\text {tot }}[\mathrm{kWh}]\right)$. In other words, the weights of Eq. 3 are represented by the ratio between the energy produced by the system $i$
$\left(E_{i}[\mathrm{kWh}]\right)$ and the energy totally required by the network:

$x_{i}=\frac{E_{i}}{E_{t o t}}$

To better understand the proposed approach, some considerations about the first law efficiency and the pollution indicator have been made for various energy systems:

- Combined heat and power (CHP) units: $\eta_{I}=$ $\eta_{e}+\eta_{t h}$ (where $\eta_{e}$ is the electrical efficiency and $\eta_{e}$ is the thermal efficiency) and $I P=$ $f$ (natural gas) can be evaluated as a function of the natural gas $(\mathrm{NG})$ composition. It results always $I P>0$.

- Natural gas boilers: $\eta_{I}=\eta_{t h}$ and $I P=$ $f$ (natural gas) $>0$.

- Biomass boilers: $\eta_{I}=\eta_{t h}$ and $I P=$ $f$ (biomass $)>0$.

- Waste To Energy (WTE) applied to DHNs: $\eta_{I}=$ $\eta_{e}+\eta_{t h} \quad$ and $\quad I P=$ $f$ (municipal solid waste $)>0$.

- Thermal solar panels: $\eta_{I}=\eta_{t h}$ and $I P=0$

- Photovoltaic (PV) panels: $\eta_{I}=\eta_{e}$ and $I P=0$.

- Electricity purchased from the grid: both the first law efficiency and the pollution indicator must be evaluated considering a reference (e.g. national, European or global) energy production mix and the related mean efficiency.

For heat pumps, compression chillers and absorption chillers - since the energy they require as input is not a primary energy - a different evaluation can be made. The users' needs fulfilled by these systems, indeed, can be attributed to those systems who provide the energy input or to the national electric grid. As an example, if the electricity in input of a heat pump has been produced via PV panels, it will be accounted in the weighted ecological efficiency related to PV panels; on the other hand, if that electricity is purchased from the grid, it will be accounted in the evaluation of the weighted ecological efficiency related to the electricity from the grid. As a consequence, the energy totally required by the network $\left(E_{\text {tot }}[\mathrm{kWh}]\right.$ in Eq.4) can be evaluated as:

$E_{t o t}=E_{e, u}+E_{e, H P}+\left(E_{t h, u}-E_{t h, H P}\right)+E_{e, C C}+$

$E_{t h, A C}$

where $E_{e, u}[\mathrm{kWh}]$ is the electrical energy required by the users connected to the network, $E_{e, H P}[\mathrm{kWh}]$ is the electrical energy in input to the heat pump, $\left(E_{t h, u}-\right.$ $\left.E_{t h, H P}\right)$ - being both the quantities expressed in [kWh] - is the thermal energy required by the users reduced by the amount satisfied by means of the heat pump, $E_{e, C C}$ [kWh] is the electrical energy in input to the compression chiller and $E_{t h, A C}[\mathrm{kWh}]$ is the thermal energy in input to the absorption chiller. 


\section{Case study}

As previously mentioned, in order to evaluate the environmental aspects related to the complex energy networks, which are often in contrast with the economic goals, the proposed approach has been applied to a case study. In particular, the considered case study is a smallmedium network located in the North of Italy (see Figure 1), with a centralized energy generation and composed by a total of 17 users (13 residential users, a supermarket, one day hospital structure and two schools) [9]. The main parameters of the energy systems (two identical internal combustion engines operating as CHP unit, four auxiliary boilers and a heat pump) composing the centralized power station are listed in Table 1.

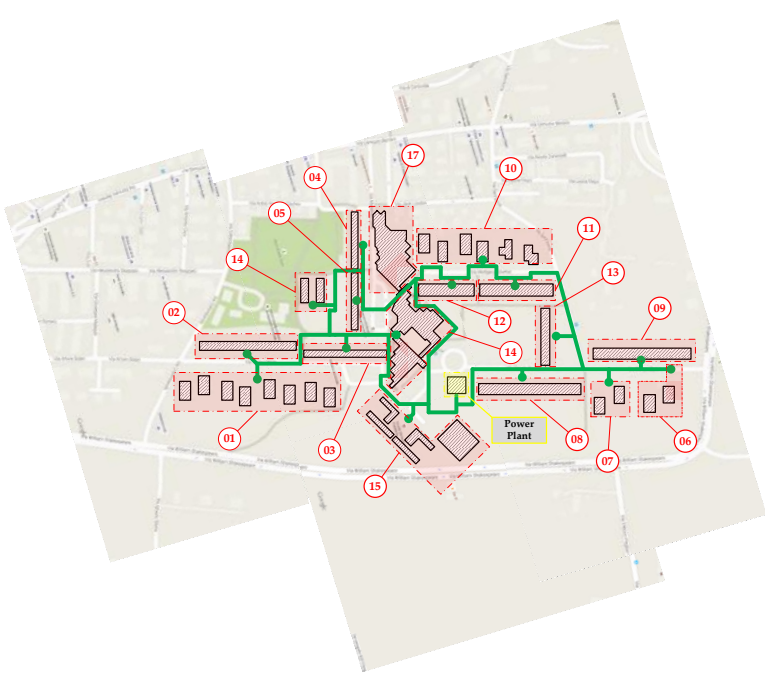

Fig. 1. Layout of the network set as case study.

Table 1. Main parameters of the energy production systems.

\begin{tabular}{|l|c|c|}
\hline \multicolumn{2}{|l|}{ Internal Combustion Engine (each) } \\
\hline Fuel Type & & Natural Gas \\
\hline Design Electric Power & {$[\mathrm{kW}]$} & 730 \\
\hline Design Thermal Power & {$[\mathrm{kW}]$} & 778 \\
\hline Design Electrical Efficiency & {$[-]$} & 0.4161 \\
\hline Design Thermal Efficiency & {$[-]$} & 0.4425 \\
\hline Natural Gas Auxiliary Boilers & {$[\mathrm{kW}]$} & $11^{\circ} 600$ \\
\hline Design Thermal Power & {$[-]$} & 0.80 \\
\hline Design Thermal Efficiency & {$[\mathrm{kW}]$} & $20^{\circ} 000$ \\
\hline Heat Pump & \multicolumn{2}{|l}{} \\
\hline Design Thermal Power & \multicolumn{2}{|l}{} \\
\hline COP & {$[\mathrm{k}$} & \\
\hline
\end{tabular}

For space reasons, the whole year evaluation will be not presented in this study, but a focus on the wintertime typical day will be shown. To this respect, the energy needs of the users during a typical winter day are presented in Figure 2, in terms of thermal and electrical needs (no cooling request occurs during wintertime) [9]. The thermal needs consist in space heating and hot water needs, fulfilled via district heating by the centralized thermal power station, while the electrical request is composed by the need for lighting, computers and other appliances.

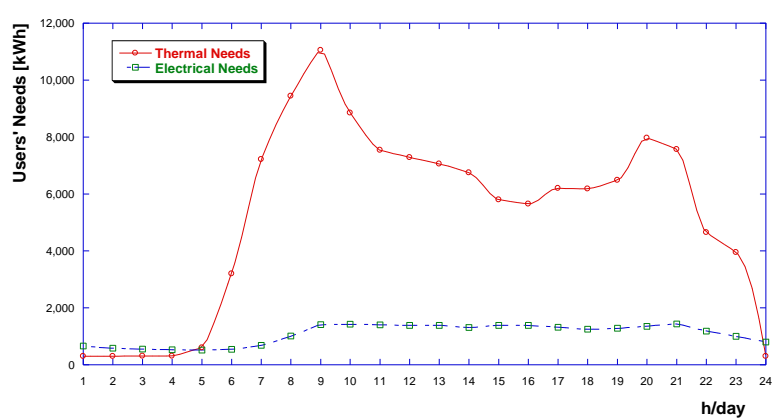

Fig. 2. Thermal and electrical needs of the network set as case study, during a typical day in wintertime.

In order to evaluate the economic and the environmental aspects related to the networks set-up and operation, the energy analysis to obtain the optimal load allocation among the various energy systems can be performed with two in-house developed optimization software [10], based on different approaches:

- minimization of the total cost of energy production, with the possibility of penalizing the introduction of electricity into the national grid and the dissipation of thermal energy through the chimney by associating them additional costs within the objective function (software EGO);

- pure economic optimization, by an objective function which minimizes the total cost of energy production (software COMBO).

Both the approaches have been evaluated in order to demonstrate that the economic and the environmental goals require often different choices in terms of set-up and/or operation of a complex energy network.

In more detail, the compared scenarios are four, including the two approaches presented in the previous paragraph and two reference cases (representing more general and traditional ways to fulfill the energy needs):

1. Current set-up - EGO optimization: in this scenario the energy systems employed to fulfill the network's needs are those presented in Table 1 and the scheduling optimization has been performed with the software EGO, including the penalization of both heat dissipation and electricity introduction into the national grid.

2. Current set-up - COMBO optimization: the scheduling optimization has been carried-out with the software COMBO, thus it is a pure economic optimization (i.e. the minimum cost for the energy production is obtained). The energy systems considered for the analysis are the same of the previous scenario. 
3. Electric Grid only: in this reference scenario it is assumed that both electrical and thermal needs of the users are satisfied by the electricity purchased from the national grid. As a consequence, the heat pump is used to fulfill the thermal needs.

4. Electric Grid + NG Boilers: in the second reference scenario the electrical needs of the users are satisfied by the purchase of electricity from the grid, while the thermal needs are satisfied via NG boilers. This case represents a traditional and common way to provide energy in urban areas.

For each scenario, an energy-economic-environmental evaluation of the typical day in wintertime has been carried-out, allowing to obtain the hourly profiles of the electrical and thermal energy to be provided, of the total cost of energy production and of the energy-ecological efficiency. In detail, on the basis of the results of the software application and of the assumptions made for the two reference scenarios, the profiles of the thermal and the electrical energies required by the whole network have been determined for each case. Then, an economic analysis aimed at the determination of the total cost of energy production has been carried out, including both the energy systems' maintenance costs and the costs for electricity and natural gas purchase. Finally, the energy-ecological efficiency has been calculated by applying the methodology presented in Section 2.

The main economic and environmental assumptions made for the analysis are listed in Table 2 [10-12].

Table 2. Economic and environmental parameters assumed for the analysis [10-12].

\begin{tabular}{|c|c|}
\hline Parameter & Value \\
\hline $\begin{array}{c}\mathrm{CO}_{2} \text { equivalent emissions NG } \\
\text { boilers }\end{array}$ & $56 \mathrm{~g} / \mathrm{MJ}$ \\
\hline $\begin{array}{c}\mathrm{CO}_{2} \text { equivalent emissions } \\
\text { Internal Combustion Engines }\end{array}$ & $284.8 \mathrm{~g} / \mathrm{kWh}$ \\
\hline $\begin{array}{c}\mathrm{CO}_{2} \text { equivalent emissions } \\
\text { National Electric Grid }\end{array}$ & $433.2 \mathrm{~g} / \mathrm{kWh}$ \\
\hline $\begin{array}{c}\text { Mean efficiency (electricity } \\
\text { from the National Grid) }\end{array}$ & $42.7 \%$ \\
\hline NG cost & $0.075 € / \mathrm{kWh}$ \\
\hline $\begin{array}{c}\text { Cost of electricity purchase } \\
\text { p.m.), } 0.125 € / \mathrm{kWh}(9 \\
\mathrm{p} . \mathrm{m} .-8 \mathrm{a} . \mathrm{m})\end{array}$ \\
\hline $\begin{array}{c}\text { Maintenance cost Internal } \\
\text { Combustion Engines }\end{array}$ & $0.020 € / \mathrm{kWh}$ \\
\hline Maintenance cost NG boilers & $0.005 € / \mathrm{kWh}$ th \\
\hline $\begin{array}{c}\text { Maintenance cost heat pump } \\
0.010 € / \mathrm{kWh} \text { th }\end{array}$ \\
\hline
\end{tabular}

\section{Results}

The energy results, obtained for the four analyzed scenarios, are presented in Figure 3 in terms of hourly profiles of the electrical and fuel energies totally required by the network set as case study. As it can be seen, depending on the considered energy systems and strategy for the fulfillment of the users' needs, different results can be obtained. Focusing on the current production systems set-up (Figure $3 a$ and Figure $3 b$ ), it can be observed that the pure economic approach of the software COMBO causes an important decrease in the fuel consumption at the centralized power station with a corresponding increase in the electricity purchase. This evidence is due to the reduction in both the CHP units and the NG boilers operation and to the increase in the heat pump employment.
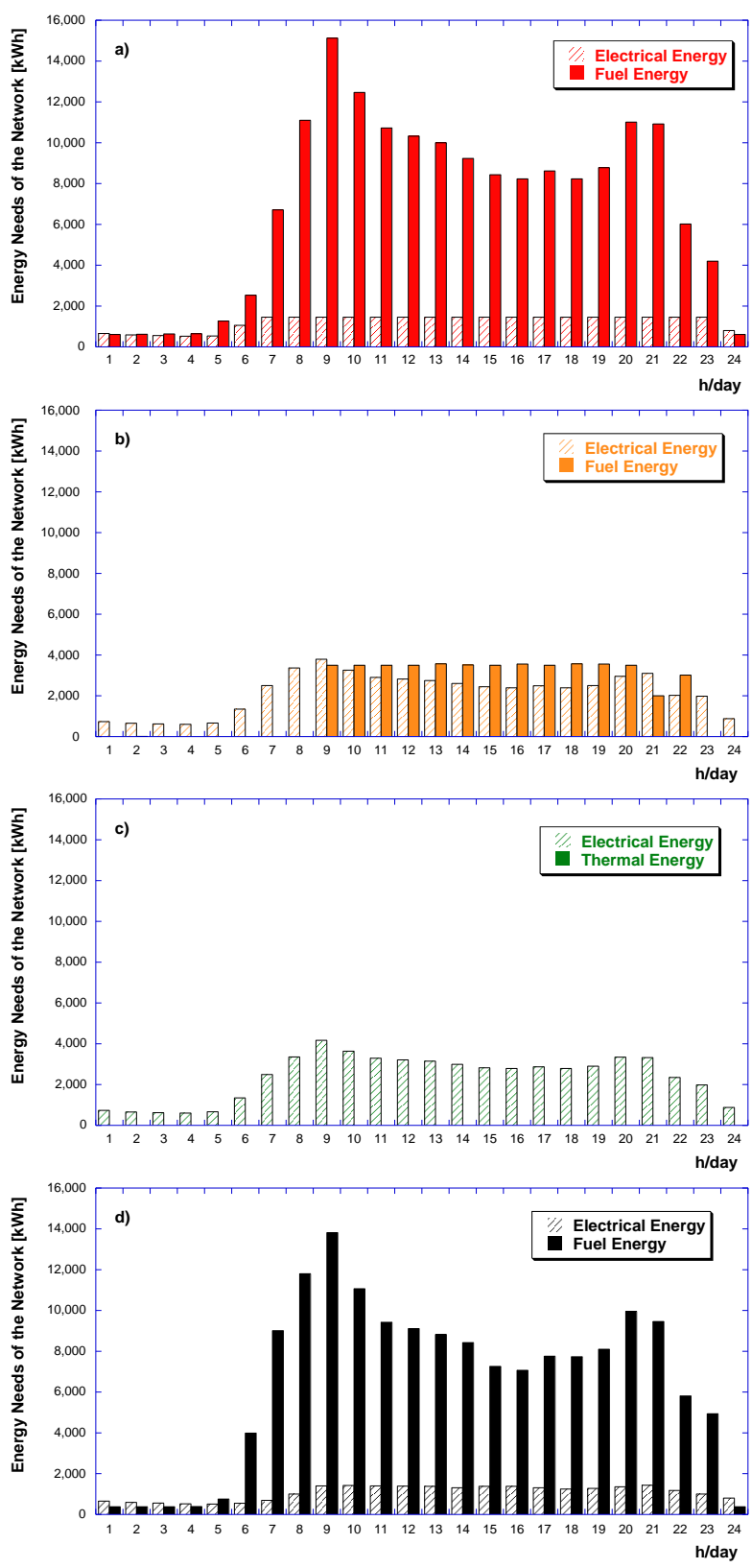

Fig. 3. Total energy needs of the network, divided between electrical and fuel energy request for: a) Current set-up - EGO optimization, b) Current set-up - COMBO optimization, c) Electric Grid only and d) Electric Grid + NG Boilers. 
Obviously, in the Electric Grid only scenario (Figure $3 c)$ all the needs are satisfied by the electricity purchase, employing the heat pump to produce the heat required by the users. This implies the maximum amount of electricity to be purchased from the national electric grid in comparison with the other analyzed scenarios. Finally, the results of the case Electric Grid + NG Boilers (Figure 3d) are quite similar to those of the current set-up - EGO optimization, with slight variations in opposite directions during the daily and the nightly hours: during the night, indeed, the EGO optimization causes the operation of the CHP units, with the consequent fuel consumption, while in the last analyzed scenario a higher share of electricity purchase is registered; on the contrary, during the daily hours the fuel consumption share is lower for the EGO optimization due to the employment of heat pumps instead of NG boilers.

Relating to the economic analysis, the results are presented in Figure 4 in terms of hourly profiles of the total cost of energy production, for the four analyzed scenarios. As a confirmation of the approach validity, the minimal costs are obtained with the current set-up COMBO optimization. In detail, during the nightly hours a slight variation can be seen depending on the considered scenario, with the Electric Grid only and current set-up - COMBO optimization both showing the minimal cost of energy production (i.e. the whole needs are satisfied with electricity purchase even if CHP units and NG boilers are included within the possible production systems). This evidence is mainly due to the low energy demand occurring during the night and considering the size of the NG fueled energy systems. Furthermore, from 6 a.m. to 8 a.m. and from 9 p.m. to 11 p.m. the results of the Electric Grid only and current set-up - COMBO optimization cases are again almost coincident, but the other two analyzed scenarios importantly increase the associated cost of energy production, due to the wide use of internal combustion engines (ICEs) and NG boilers. Finally, from 9 a.m. to 8 p.m. the worst economic performance are observed for the Electric Grid + NG Boilers scenario, while the minimal cost is obtained with the COMBO optimization which allows an almost complete shut down of the NG boilers, operating the ICEs and the heat pump in the optimal economic way. To this respect, being the thermal needs high during the daily hours, the Electric Grid only strategy is penalized.

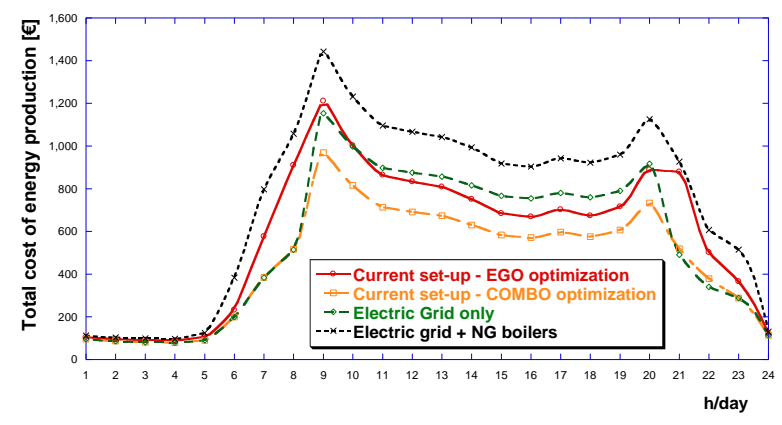

Fig. 4. Total cost of energy production for the four analyzed scenarios.
In order to evaluate the energy-ecological efficiency of the network set as case study, the first law efficiency, the pollutant indicator and the energy-ecological efficiency of each energy system must be evaluated. Considering the natural gas boilers and the electricity purchased from the grid, the first law efficiency can be considered respectively equal to the thermal efficiency $(80 \%$, see Table 1) and to the mean efficiency of the national thermal power plants $(42.7 \%$, see Table 2$)$. Furthermore, the values of the IP and the energyecological efficiency obtained for the NG boilers and the electricity from the grid are listed in Table 3. Evidently, for the electricity from the grid, these parameters are constant and independent from the considered scenario, since mean values of the national electric grid have been considered. In addition, the IP and $\eta_{\text {eco }}$ values result constant also for the NG boiler, having kept constant its efficiency.

Table 3. Environmental analysis results for the NG boilers and the electricity from the grid.

\begin{tabular}{|c|c|}
\hline Parameter & Value \\
\hline IP NG boilers & $0.0560 \mathrm{~kg} / \mathrm{MJ}$ \\
\hline IP National Electric Grid & $0.1203 \mathrm{~kg} / \mathrm{MJ}$ \\
\hline$\eta_{\text {eco,NG boilers }}$ & $93.51 \%$ \\
\hline$\eta_{\text {eco,electricity grid }}$ & $78.05 \%$ \\
\hline
\end{tabular}

Relating to the CHP units, instead, the pollutant indicator results equal to $0.0791 \mathrm{~kg} / \mathrm{MJ}$, but the values of the first law efficiency and, thus, also of the energyecological efficiency varies depending on the considered hour during the day (i.e. on the amount of produced electricity and recovered heat) and on the considered scenario (EGO or COMBO optimization). In particular, the first law efficiency varies from $85.85 \%$ to $85.96 \%$ for the EGO optimization, while from 84.64 $\%$ to $85.87 \%$ for the COMBO optimization. The higher values obtained with $\mathrm{EGO}$ are due to the characteristics of its objective function, which allows to maximize the heat recovery (by penalizing the heat dissipation through the chimney) and to minimize the electricity introduction into the network. The pure economic optimization made with COMBO, indeed, causes a slight decrease in the energy conversion efficiency. As a consequence, the obtained values of the energyecological efficiency are equal to around $91.61 \%$ for EGO and in the range $91.5-91.6 \%$ for COMBO.

Based on the results presented above, the trends of the energy-ecological efficiency of the whole network have been calculated with the methodology described in Section 2. The results are presented in Figure 5. 


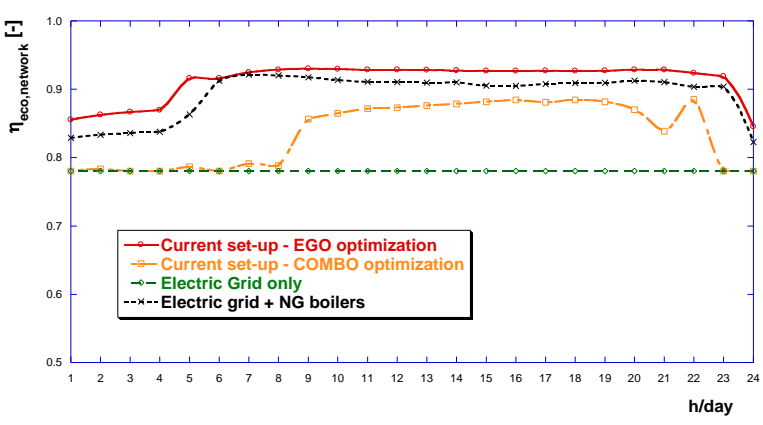

Fig. 5. Energy-ecological efficiency profile for the four analyzed scenarios.

As it can be seen, the results of the environmental analysis are in opposition to the economic results. Indeed, the worst situation is observed for the Electric Grid only scenario, with a constant energy-ecological efficiency equal to around the $78 \%$, followed by the COMBO optimization which presents a virtuous behavior during the daily hours but low energyecological efficiencies during the night. On the contrary, the optimization made with EGO, based on an economic objective function modified to penalize the thermal energy dissipations and the surplus of electricity production, allows to achieve the higher values of the energy-ecological efficiency with a maximum slightly higher than $93 \%$ (at 9 a.m.).

The obtained results indicate that the employment of energy systems, such as CHP units and heat pumps, causes a penalization from an economic viewpoint but it is largely encouraged to reduce the environmental impact in the energy production field. Furthermore, these aspects would probably result emphasized considering distributed generators from renewable energy sources and including the related high investment costs. As a consequence, opportune incentive policies are fundamental to achieve the environmental goals imposed for the next years in a perspective of sustainability.

For these reasons, future studies will investigate the possibility of defining a novel optimization tool with an objective function able to optimize the design and the scheduling of a complex energy network including all the aspects discussed above.

\section{Concluding Remarks}

The aim of the paper stands in the development of an energy-economic-environmental methodology for the complete evaluation of complex energy networks for the electrical, thermal and cooling energies fulfillment of the connected users. With this purpose, the definition of an energy-ecological efficiency from literature has been extended for the first time to the complex energy networks. Furthermore, a case study represented by a middle size network for the complete fulfillment of the connected users' energy needs has been analyzed applying the proposed methodology to different scenarios in terms or energy production mix and operation (optimized by means of in-house developed software with objective functions which follow two approaches: pure economic or penalizing heat dissipation and electricity introduction into the grid).

The obtained results indicate that the fulfillment of the whole energy needs by the electricity purchase only is the most economical solution, but with the higher associated environmental impact. On the contrary, the employment of energy systems, such as CHP units and heat pumps, causes a penalization from an economic viewpoint but presents the best performance from an environmental perspective. The difference between economic and environmental optimizations will be increased in presence of renewable generators, maxing fundamental national and international incentive policies. For these reasons, future works will be aimed at developing a further optimization tool with an objective function able to optimize the design and the scheduling of a complex energy network including energy, economic and environmental goals.

\section{References}

1. M. S. Smith, C. Cook, Y. Sokona, T. Elmqvist, K. Fukushi, W. Broadgate, M. P. Jarzebski, Sustain. Sci. 13, 1483 (2018)

2. D. Connolly, H. Lund, B. V. Mathiesen, S. Werner, B. Möller, U. Persson, T. Boermans, D. Trier, P. A. Østergaard, S. Nielsen, Energy Policy 65, 475 (2014)

3. Proposal for a REGULATION OF THE EUROPEAN PARLIAMENT AND OF THE COUNCIL establishing the framework for achieving climate neutrality and amending Regulation (EU) 2018/1999 (European Climate Law). Available at: https://eur-lex.europa.eu/legalcontent/EN/TXT/?qid=1588581905912\&uri=CEL EX:52020PC0080 (2020)

4. R. Marah, A. El Hibaoui, Sustain Cities Soc. 38, 627 (2018)

5. M. Cardu, M. Baica, Energ Convers Manage 40(1), 71 (1999)

6. M. Cardu, M. Baica, Energ Convers Manage 40(14), 1569 (1999)

7. I. A. de Castro Villela, J. L. Silveira, Appl Therm Eng 27, 840 (2007)

8. M. L. Carneiro, M. S. Gomes, Energ Convers Manage 179, 397 (2019)

9. M. A. Ancona, L. Branchini, A. De Pascale, B. Di Pietra, F. Melino, G. Puglisi, F. Zanghirella, AIP Conference Proceedings 2191, 020007 (2019)

10. M. A. Ancona, M. Bianchi, L. Branchini, A. De Pascale, F. Melino, A. Peretto, J. Rosati, Proceedings of the ASME Turbo Expo (to be published)

11. Istituto Superiore per la Protezione e la Ricerca Ambientale (ISPRA). Available at: https://www.isprambiente.gov.it/it/banchedati/banche-dati-folder/aria-ed-emissioni-inatmosfera

12. Ministry of the Environment. Available at: https://www.minambiente.it/ 